\title{
ALGUMAS CONSIDERAÇÕES SOBRE A FUNÇÃO DA CONSCIÊNCIA A PARTIR DAS PROPAGANDAS DA REFORMA DO ENSINO MÉDIO
}

\author{
Márcia Sabina Rosa Blum ${ }^{1}$ \\ Maria Sara de Lima Dias ${ }^{2}$ \\ Domingos Leite Lima Filho ${ }^{3}$
}

\begin{abstract}
RESUMO
O presente artigo tem por intuito trazer algumas considerações sobre a função da consciência a partir das propagandas veiculadas sobre a Reforma do Ensino Médio. As duas propagandas escolhidas foram veiculadas no período de tramitação da Medida Provisória 746/2016, um contexto conturbado em meio a protestos e manifestações contrárias À reforma. Para colaborar nesse debate trar-se-á as discussões de Vygotski (1990a, 1990b) que concebe a consciência como um mecanismo que mobiliza as experiências histórica, social e duplicada. A partir desse processo reflexivo é que se chega ao reflexo condicionado e não a um mero produto de um estímulo. Williams (2016), com a discussão da televisão na sua dupla função: tanto como um aparato tecnológico quanto como forma cultural, auxilia na compreensão da televisão dentro de um espaço de disputas e não numa simples relação de causa e efeito. Pelo fato de os jovens refletirem sobre as informações veiculadas e colocá-las numa cadeia de reflexos e conhecimentos, a consciência adquire um papel primordial na formação do ser humano: ativa a memória, a atenção, a percepção do entorno social para formulação de conceitos, e o faz a partir da realidade histórica, social e individual, por isso a imprevisibilidade do comportamento humano.
\end{abstract}

Palavras-chave: Reforma do Ensino Médio. Consciência. Propaganda. Televisão.

\section{SOME CONSIDERATIONS ON THE FUNCTION OF CONSCIOUSNESS FROM} THE ADVERTISEMENT OF THE HIGH SCHOOL REFORM

\section{ABSTRACT}

The present article intends to bring some considerations about the function of the conscience from the advertisements propagated about the Reformation of the Secondary School. The two selected advertisements were transmitted during the period covered by Provisional Measure 746/2016. A troubled context during protests against the reform. In order to collaborate in this discussion, Vygotsky $(1990,1990$ a) discusses consciousness as a mechanism that mobilizes historical, social and duplicate experiences. From this process reflexive is that it arrives at the conditioned reflex and not only as a product of a stimulus. Williams (2016) with the discussion of television in its dual function: both as a technological apparatus and as a cultural form. It assists in the understanding of television within a space of disputes and not in a simple relation of cause and effect. The fact that young people reflect on the information conveyed and place them in a chain of reflexes and knowledge, the conscience acquires a primordial role in the formation of the human being. Activates the memory, the attention, the perception of the social surroundings for the formulation of concepts. And it does so from the historical reality, social and individual, therefore the unpredictability of human behavior.

Keywords: High School Reform. Consciousness. Propaganda. Television.

RECEBIDO EM: 21/10/2019

ACEITO EM: $16 / 11 / 2019$

\footnotetext{
1 Autora correspondente. Universidade Estadual do Paraná - Unespar, Campus de Curitiba II. Rua dos Funcionários, 1357 - Cabral. Curitiba/ PR, Brasil. http://lattes.cnpq.br/5814018966940322. https://orcid.org/0000-0001-6069-5746. marciasabina@hotmail.com

2 Universidade Tecnológica Federal do Paraná. Curitiba/PR, Brasil. http://lattes.cnpq.br/4807954398668607. http://orcid.org/0000-00017296-6400.

3 Universidade Tecnológica Federal do Paraná. Curitiba/PR, Brasil. http://lattes.cnpq.br/1113538527015820. https://orcid.org/0000-0003$3802-6794$
} 
Pretende-se, neste estudo, trazer algumas considerações a respeito da função da consciência a partir das propagandas veiculadas sobre a Reforma do Ensino Médio. A Reforma do Ensino Médio foi proposta a partir da Medida Provisória - MP 746/2016 e depois viabilizada pela Lei 13.415/2017. Para que tal proposta tivesse um semblante de consenso da maioria e também como forma de "esclarecer" a população sobre a referida reforma, foram veiculadas, a partir do dia 28 de setembro de 2016, duas propagandas televisivas do Ministério da Educação/governo federal para tais "elucidações", isso durante a tramitação da MP.

A propaganda é um dos meios em que as disputas sociais também se expressam e vão para além da linguística. Nesse sentido, a escolha pelas duas propagandas veiculadas durante a tramitação da MP se dá pelo contexto conturbado em meio a protestos e manifestações contrárias à reforma, o que evidencia um processo de disputas e consensos de classe.

Para colaborar nessa discussão trar-se-á Williams (2016), que discute a televisão tanto como um aparato tecnológico quanto como forma cultural. Williams, segundo Schiavoni (2016, p. 233), ressalta essa duplicidade já no prefácio do livro intitulado "Televisão: tecnologia e forma cultural", pois concebe a televisão como campo de disputas, por isso não é determinada e pode produzir ou não os efeitos esperados, conforme aponta:

[...], todas as perguntas sobre causa e efeito, como entre uma tecnologia e uma sociedade, são intensamente práticas. Até começarmos a respondê-las, realmente não sabemos, em cada caso concreto, se, por exemplo, estamos falando de uma tecnologia ou dos usos de uma tecnologia; de instituições essenciais ou instituições particulares e mutáveis; de um conteúdo ou de uma forma. E isso não é só uma questão de incerteza intelectual, é uma questão de prática social. Se a tecnologia é uma causa, podemos, na melhor das hipóteses, modificar ou procurar controlar seus efeitos. Se a tecnologia, como é usada, é de fato um efeito, a que outros tipos de causa e outros tipos de ação devemos nos referir e relacionar a nossa experiência de seus usos? Essas não são questões abstratas, ocupam um lugar cada vez mais importante em nossos debates sociais e culturais, e, na prática, tomamos decisões concretas e efetivas sobre elas a todo o tempo (WILLIAMS, 2016, p. 24).

No cerne do debate, a dicotomia entre causa e efeito deve ser superada. Neste sentido, Vygotski (1990) ${ }^{4}$, quando discute sobre a consciência, deixa claro que a reflexologia ignora este aspecto do homem quando trata somente do comportamento humano como reflexo e adaptação ao meio. $O$ autor alerta que a psicologia, ao ignorar o problema da consciência, "está fechando em si mesma o caminho da investigação dos problemas mais ou menos complexos do comportamento humano"5 (VYGOTSKI, 1990a, p. 1). Por isso, o interesse neste aspecto da Psicologia, juntamente com reflexões sobre como esses processos são intermediados pela propaganda televisiva de modo a entrelaçar com o nosso objeto de pesquisa: a Reforma do Ensino Médio.

\footnotetext{
${ }_{4}^{4}$ Publicado originalmente no 2ㅇ Congresso Nacional de Psiconeurologia em 1924.

5 “está cerrando a sí misma El camino de la investigación de problemas más o menos complejos del comportamiento humano"
} 
Este artigo está assim dividido: introdução, na qual explana-se os objetivos e os autores que serão referenciados; na sequência, com o subtítulo $A$ televisão e a consciência como meios de formação humana, trata sobre o conceito de consciência e sua função a partir de alguns capítulos das Obras Escolhidas de Vygostski (1990a), como também da função da televisão a partir da obra Televisão: tecnologia e forma cultural de Raymond Williams (2016), já citada nesse tópico; finaliza-se com o tópico A propaganda da Reforma do Ensino Médio, o qual se propõe em responder à questão principal desta pesquisa de cunho bibliográfica, a qual é: Qual a função da consciência no processo de formação humana? A partir disso serão apresentadas algumas considerações baseadas no exposto.

\section{A TELEVISÃO E A CONSCIÊNCIA COMO MEIOS DE FORMAÇÃO HUMANA}

Vygotski (1990a), em seus textos, tem por objetivo propor uma Psicologia pautada nos princípios do materialismo histórico-dialético, a que chama de Psicologia dialética. Assim sendo, discute, dentre várias questões, a consciência e faz uma crítica às Psicologias existentes, em especial por ignorarem a dimensão dialética em suas proposições.

Nos capítulos do livro "Obras escogidas I - Problemas teóricos y metodológicos de la psicología", Vygotski mostra que o comportamento animal é diferente do comportamento humano, pois esse é social e se adapta ativamente ao meio, diferentemente dos animais ${ }^{6}$. O autor, no capítulo intitulado "A consciência como problema da psicologia do comportamento" ${ }^{\prime \prime}$, quando traz a citação de Marx ${ }^{8}$ sobre a aranha e o arquiteto, formula um novo conceito que chama de experiência duplicada do trabalho humano, que nada mais é do que a capacidade de o homem prever idealmente aquilo que irá executar; por isso trata-se de uma experiência duplicada, sendo também chamada de adaptação ativa.

O comportamento do homem não é somente a expressão de reflexos condicionados, mas se constitui de: "[...]: experiência histórica, experiência social, experiência duplicada"9 (VYGOTSKI, 1990a, p. 5). Ou seja, esse é o mecanismo para que se chegue ao reflexo condicionado e é o processo que o autor chama de consciência ou o que a constitui.

\footnotetext{
6 Vygotski não ignora o fato do pensamento ativo também fazer parte dos animais, mas deixa claro que esse não é dominante e fundamental neles (VYGOTSKI, 1990a, p. 5).

"La conciencia como problema de la psicología del comportamiento".

8 "[...]. Uma aranha executa operações semelhantes às do tecelão, e a abelha supera mais de um arquiteto ao construir sua colméia. Mas o que distingue o pior arquiteto da melhor abelha é que ele figura na mente sua construção antes de transformá-la em realidade. No fim do processo do trabalho aparece um resultado que já existia antes idealmente na imaginação do trabalhador. Ele não transforma apenas o material sobre o qual opera; ele imprime ao material o projeto que tinha conscientemente em mira, o qual constitui a lei determinante do seu modo de operar e ao qual tem de subordinar sua vontade. Além do esforço dos órgãos que trabalham, é mister a vontade adequada que se manifesta através da atenção durante todo o curso do trabalho. $\mathrm{E}$ isto é tanto mais necessário quanto menos se sinta o trabalhador atraído pelo conteúdo e pelo método de execução de sua tarefa, que lhe oferece, por isso, menos possibilidade de fruir da aplicação de suas próprias forças físicas e espirituais" (MARX, 2014, p. 211-212).

9 Fórmula do comportamento humano para Vygotski; “[...]: experiencia histórica, experiencia social, experiencia duplicada".
} 
O homem tem inúmeros comportamentos possíveis ainda não realizados; por isso, Vygotski trata deste processo como uma luta constante de forma concomitante nos campos fisiológico, biológico e social. Essa luta nada mais é do que "[...] interação, reflexão, excitação recíproca de diferentes sistemas de reflexos. [...]"10 (VYGOTSKI, 1990a, p. 8), e esse é o papel regulador da consciência. Ou seja, a consciência é um mecanismo de transmissão e, juntamente como os sentimentos e a vontade, compõe a subjetividade.

O autor explana sobre os sistemas excitantes e reflexos que são reversíveis. Esses sistemas, pode-se dizer, são frutos da interação do homem em seu meio social e produzem ações e são reversíveis na medida em que os sistemas excitantes podem ser um reflexo e os reflexos podem ser excitantes.

A ciência do homem concreto, no estudo da consciência humana, não pode se limitar ao mundo concreto e material limitado ou a ela mesma. A ciência do comportamento do homem deve sair dos limites do experimento clássico na modalidade estímulo e resposta. Quando estamos estudando a consciência só temos acesso a ela por meio da linguagem.

Deste modo, a linguagem assume um papel primordial tanto como excitante ou como reflexo, por ser, por um lado, um sistema de reflexos do comportamento social e, de outro, da consciência de si mesmo. A esse respeito Vygotski acrescenta (1990a):

Portanto, como consequência da adoção da hipótese proposta se conduzirá diretamente a socialização de toda a consciência, dela se desvincula que o reconhecimento, a prioridade temporal e efetiva pertencem ao aspecto social e à consciência. $\mathrm{O}$ aspecto individual se constrói como derivado e secundário da base social e segundo seu exato modelo. Eis a idéia da dualidade da consciência: a idéia de dupla está mais próxima da idéia real da consciência ${ }^{11}$ (p. 12).

Deste modo, os excitantes sociais são, para Vygotski, os que mais se destacam e evidenciam as relações sociais humanas como primordiais para o desenvolvimento da consciência de si mesmos a partir dos outros e a consciência dos outros a partir daquilo que produziu em si mesmo, numa relação dialética. Assim, continua o autor:

Dito isso, fica fácil distinguir no homem um grupo de reflexos, cuja denominação correta seria a de um sistema de reflexos de contato social (A. B. Zalking). Se tratam de reflexos que se relacionam a excitantes que são criados pelo homem. A palavra ouvida é um excitante, a palavra pronunciada é um reflexo que cria esse mesmo excitante. Estes reflexos reversíveis, que originam uma base para a consciência (entrelaçamento de reflexos), servem de fundamento da comunicação social e da coordenação coletiva do comportamento, o que indica, entre outras coisas, a origem social da consciência.[...] ${ }^{12}$ (VYGOTSKI, 1990b, p. 6).

\footnotetext{
10 "[...] interacción, reflexión, excitación recíproca de diferentes sistemas de reflejos. [...]"

${ }^{11}$ Por eso, como consecuencia de la adopción de la hipótesis propuesta se seguirá directamente la socialización de toda la conciencia, de ello se desprende que el reconocimiento, la prioridad temporal y efectiva pertenecen a la vertiente social y a la conciencia. La vertiente individual se construye como derivada y secundaria sobre la base de lo social y según su modelo exacto. De aquí la dualidad de la conciencia: la idea del doble es la más cercana a la idea real de la conciencia.

${ }^{12}$ De hecho, es fácil distinguir en el hombre un grupo de reflejos, cuya denominación correcta sería la de sistema de reflejos de contacto social (A. B. Zalkind). Se trata de reflejos que reaccionan a excitantes que a su vez son creados por el hombre. La palabra oída es un excitante, la palabra pronunciada es un reflejo que crea ese mismo excitante. Estos reflejos reversibles, que originan una base para la conciencia (entrelazamiento de reflejos), sirven de fundamento a la comunicación social y a la coordinación colectiva del comportamiento, lo que indica, entre otras cosas, el origen social de la conciencia. [...].
} 
Considera-se que a consciência é um produto social da qual decorre, de forma derivada e secundária, a consciência individual e a constituição da subjetividade.

O sujeito é constituído pelas ferramentas, símbolos, signos e significados historicamente produzidos por relações sociais, e age sobre o mundo com a capacidade de regular a sua ação, formando, assim, sua subjetividade individual. Não se trata de um indivíduo universal, mas de uma ontologia do ser social, que constitui um sistema de sentidos e significados subjetivamente apropriados, que constrói a subjetividade do homem a partir das relações sociais que estabelece.

É neste sentido que a Psicologia proposta por Vygotski vem se diferenciar das demais Psicologias existentes. $\mathrm{O}$ autor supracitado tece críticas às Psicologias tradicional, compreensiva ou descritiva, objetiva (Reflexologia/Behaviorismo) e à Psicanálise, pois estas tentam explicar os fenômenos psíquicos partindo deles mesmos ou desconsideram esses fenômenos completamente. Ele, então, complementa:

[...]. O homem não se serve unicamente da experiência herdada fisicamente. Toda nossa vida, o trabalho, o comportamento, tem como base a amplíssima utilização da experiência das gerações anteriores, é dizer, de uma experiência que não se transmite de pais para filhos por meio do nascimento. A chamamos convencionalmente de experiência histórica.

Junto a ela deve situar a experiência social, a de outras pessoas, que constituem um importante componente do comportamento do homem. Dispõe não somente das conexões que se resumem na minha experiência particular entre os reflexos condicionados e elementos isolados do meio, como também das numerosas conexões que têm sido estabelecidas na experiência de outras pessoas. Se conheço o Saara e Marte, apesar de não ter saído uma vez sequer do meu país e de não ter olhado jamais através de um telescópio, se deve que essa experiência tem sua origem na de outras pessoas que foram ao Saara e olharam por meio de um telescópio. É evidente que os animais não possuem essa experiência. A designamos como componente social do nosso comportamento ${ }^{13}$ (1990a, p. 5).

\footnotetext{
${ }^{13}$ [...]. El hombre no se sirve únicamente de la experiencia heredada físicamente. Toda nuestra vida, el trabajo, el comportamiento, se basan en la amplísima utilización de la experiencia de las generaciones anteriores, es decir, de una experiencia que no se transmite de padres a hijos a través del nacimiento. La llamaremos convencionalmente experiencia histórica.

Junto a ello debe situarse la experiencia social, la de otras personas, que constituye un importante componente del comportamiento del hombre. Dispongo no sólo de las conexiones que se han cerrado en mi experiencia particular entre los reflejos condicionados y elementos aislados del medio, sino también de las numerosas conexiones que han sido establecidas en la experiencia de otras personas. Si conozco el Sahara y Marte, a pesar de no haber salido ni una sola vez de mi país y de no haber mirado jamás a través del telescopio, se debe evidentemente a que esta experiencia tiene su origen en la de otras personas que han ido al Sahara y han mirado por el telescopio. Es igual de evidente que los animales no poseen esta experiencia. La designaremos como componente social de nuestro comportamiento.
} 
Nessa linha de pensamento, Vygotski vem afirmar que a experiência histórica e a experiência social são psicologicamente congêneres, por isso sempre se apresentam juntas na realidade. Desse modo, a consciência deve ser considerada "[...] como um caso particular da experiência social. Por isso, é fácil designá-la com o mesmo indicador da experiência duplicada"14 (VYGOTSKI, 1990a, p. 13).

A consciência é, ao mesmo tempo, um mecanismo de transmissão entre sistemas de reflexos, por isso não é um reflexo e nem um excitante, como também a conexão que encerra esta experiência histórica particular dos sujeitos.

Após tratar do conceito de consciência em Vygotski, trar-se-á Raymond Williams (2016), que discute, em seu livro "Televisão: tecnologia e forma cultural"15, a dupla função da televisão.

É importante salientar que a posição de Williams é o materialismo cultural. O autor utiliza a palavra cultura tanto para designar modos de vida quanto para designar as artes e o aprendizado. De forma a complementar, cultura para o autor é produção, e, por isso, são práticas sociais, e o "objetivo da análise materialista é desvendar as condições dessa prática e não meramente elucidar os componentes de uma obra" (CEVASCO, 2001, p. 160).

A edição em português do referido livro foi publicada em 2016 com o prefácio de Turner $^{16}$. Nesse, Turner enfatiza que Williams "[...] rejeita amplamente os relatos dos efeitos sociais da tecnologia que ficaram identificados com alguns aspectos principais da pesquisa norte-americana sobre comunicação de massa [...]" (WILLIAMS, 2016, p. 8).

Em outras palavras, Williams refuta as pesquisas que consideram a televisão no âmbito de um determinismo tecnológico ${ }^{17}$. Deste modo, recusa "a proposição de que a televisão - como uma tecnologia - exerce efeito causal, determinante sobre o comportamento humano [...]" (WILLIAMS, 2016, p. 9). A história é, para Williams, o determinante social e da própria televisão, por isso afirma:

Se eliminarmos a história, no sentido de tempos e lugares reais, podemos conceber uma natureza humana abstrata com necessidades psíquicas específicas, a que formas variadas de tecnologia e de relações sociais vêm satisfazer. Esse modelo puramente idealista da natureza humana pode ter culminações específicas variáveis - o fim da alienação, a redescoberta da tribo -, mas, nesse processo, a tecnologia é sempre uma efusão humana, a extensão de um membro ou sentido. Somente podemos acreditar no destino e no processo se considerarmos que existe uma essência humana à espera de se realizar nesses modos, com propósitos metafisicamente inatos, se ainda não concretizamos [...] (WILLIAMS, 2016, p. 138).

\footnotetext{
$\overline{14}$ "[...] como un caso particular de la experiencia social. Por eso, es fácil designarlas con el mismo índice de experiencia duplicada.

${ }^{15}$ Essa obra foi publicada em 1974, revisada por seu filho Ederyn Williams e publicada, numa segunda edição, em 2003.

${ }^{16}$ Graeme Turner é nascido em 1947. É professor emérito da Universidade de Queensland na Austrália. Suas pesquisas são direcionadas a estudos culturais e mídia, sendo a televisão e as novas mídias seu foco de estudo atual. Disponível em: https://researchers.uq.edu.au/researcher/7479. Acesso em: 3 ago 2018.

${ }^{17}$ Faz críticas mais contundentes a Herbert Marshall McLuhan. A obra de Williams pauta-se numa análise televisiva dos Estados Unidos e Inglaterra na década de 70.
} 
Neste aspecto, pode-se inferir que Williams (2016) se aproxima do conceito de consciência de Vygotski por considerar o homem um ser reflexivo, ou seja, as suas atitudes passam por um processo de reflexão antes de se tornarem atitudes concretas, e não é um simples estímulo e resposta, ou melhor, causa e efeito; é a concepção de experiência duplicada em Vygotski que fica evidente.

Turner (2016 apud WILLIAMS, 2016, p. 8), ainda no prefácio da edição brasileira, argumenta que em alguns aspectos a obra já foi superada. A abordagem da televisão enquanto experiência cultural, no entanto, continua importante mesmo nos dias atuais, pois aborda

[...] uma experiência engendrada pela articulação complexa entre práticas produtivas, determinantes tecnológicos e econômicos e a função social da televisão dentro do lar - assim como as estruturas formais dos gêneros televisivos individuais. É notável como essa abordagem multiperspectivada ainda se coaduna bem com as abordagens mais frequentemente recomendadas na literatura dos estudos contemporâneos sobre televisão (WILLIAMS, 2016, p. 8).

Nessa perspectiva, Williams considera que a tecnologia é desenvolvida com intencionalidades para responder a necessidades sociais de classe. Considera, porém, que

[...] a questão fundamental sobre a resposta tecnológica para uma necessidade é menos sobre a necessidade em si do que sobre seu lugar em uma formação social existente. Uma necessidade que corresponde às prioridades dos grupos reais de decisão obviamente atrairá de forma mais rápida o investimento de recursos e permissão oficial, a aprovação ou incentivo de que depende uma tecnologia de trabalho, na condição de forma distinta de dispositivos técnicos disponíveis. Podemos ver isso com clareza nos principais desenvolvimentos da produção industrial e, de modo significativo, na tecnologia militar. A história social das tecnologias de comunicação é curiosamente diferente de qualquer uma dessas, e é importante tentar descobrir os fatores reais dessa variação (WILLIAMS, 2016, p. 32).

Umas das diferenças que o autor expõe é que a base da comunicação social partiu do "boca a boca" e também de instituições específicas, como a igreja, a escola, as assembleias, e interagiam, ou melhor, são mecanismos que interagem "com as formas de comunicação na família". A necessidade para o desenvolvimento de uma nova tecnologia de comunicação social surgiu de forma dupla, segundo Williams. Pode-se destacar que foi como resposta ao desenvolvimento de um sistema social, econômico, político, e também uma resposta à crise deste próprio sistema. Mostra a imprensa como resposta a essas questões e, em meio a disputas e processos de controle, ela se torna uma instituição social.

Novas relações entre os homens e os homens e as coisas estavam sendo experimentadas após a Revolução Industrial, e as instituições tradicionais pouco podiam expor sobre isso naquele momento, pois "[...] uma conscientização maior da mobilidade e da mudança, não só como abstrações, mas como experiências vividas, levou a uma importante redefinição na prática e, logo, na teoria da função e do processo de comunicação social" (WILLIAMS, 2016, p. 34-35). 
O autor inclui que essas mudanças também podem ser vistas na fotografia e no cinema e que, principalmente após a Segunda Guerra Mundial, essas necessidades foram especializadas trazendo para cada meio de comunicação uma função específica, o que fez surgir a radiodifusão. Complementa opondo-se ao determinismo tecnológico que se liga ao processo de surgimento da radiodifusão, pois mostra que um conjunto de decisões sociais específicas, em circunstâncias particulares, não é resultado inevitável, mas decisão. Deste modo, a dupla função dos meios de comunicação, como interação social e controle, é bem evidenciada por Williams.

Nessa lógica, o autor contrapõe-se ao termo "massa"18, que passou a designar um grande número de pessoas, o qual caracteriza as produções e a própria terminologia de "comunicação de massa"19, que, para ele, é falsa, na medida em que tanto o rádio quanto a televisão foram desenvolvidos para a difusão em casas individuais. O termo "massa", para o rádio, pode ser empregado, a seu ver, na Alemanha nazista sob as ordens de Paul Joseph Goebbels, ministro da Propaganda entre 1933 a 1945, que organizou, pelo partido, grupos de audição pública obrigatórios com ouvintes na rua.

A característica principal apontada ao termo "massa" é a obrigatoriedade e não o simples fato de ser veiculado a diversas pessoas de maneira concomitante, pois considera que essas podem escolher se assistem ou não. A esse tipo de difusão chama, de modo geral, de "uma forma de consumo social unificado" (WILLIAMS, 2016, p. 40; grifo do autor). Esse conceito coaduna com sua perspectiva teórica por não considerar a imprensa, na sua forma geral, como efeito causal que produz nos homens um determinado tipo de resposta, mesmo que exista essa intencionalidade.

O autor relaciona a radiodifusão como um produto social das pressões contraditórias geradas pela fase do capitalismo industrial, ou seja, vem responder às necessidades dos processos produtivos que agora demandavam maior mobilidade interna na indústria. Isso teve consequências secundárias, tais como a dispersão das famílias extensas, o distanciamento das áreas residenciais e os locais de trabalho e do governo. Com isso, a radiodifusão vem suprir e trazer as notícias "de fora", o que ofereceu um consumo social de música, esportes, notícias, entretenimento (WILLIAMS, 2016, p. 38-40).

Por mais que Williams tenha diferenciado o termo "massa" para um consumo individualizado, há o consumo em massa destas tecnologias postas agora como necessidade. Essa necessidade relaciona-se com a produção e consumo em massa que são centrais e indispensáveis para a extração da mais-valia e acumulação do capital.

\footnotetext{
18 Williams (2016, p. 36) destaca que "massa" "é um novo termo oitocentista de desprezo para o que era anteriormente chamado de 'turba'. A 'massa' física da revolução urbana e industrial ajudou a consolidar a expressão. Uma nova consciência radical de classe adotou o termo para expressar o material das novas formações sociais: 'organizações de massa'. O 'encontro de massa' foi um efeito físico observável. Essa descrição era tão presente no século XX que múltiplas produções em série foram chamadas falsamente, mas de forma significativa, de 'produções de massa': a palavra 'massa' passa, então, a significar grandes números (mas dentro de determinadas relações sociais assumidas) no lugar de qualquer agregado físico ou social. [...]"

19 Para o autor, o termo "comunicação em massa" para a radiodifusão representa somente uma característica geral desse meio de comunicação e considera que a utilização deste termo para caracterizar o rádio e a televisão ofuscou que esse aparato foi empregado de forma individual. O autor quer delimitar que anteriormente foi produzida uma tecnologia pública como as estradas de ferro, a iluminação das cidades, e a radiodifusão não faz parte deste tipo de tecnologia ao que chama de "privatização móvel", agora focada no lar e, ao mesmo tempo, servia para um estilo de vida móvel.
} 
Na sequência, Williams tece uma crítica ao isolamento dos meios de comunicação considerados de massa na teoria de $\mathrm{McLuhan}^{20}$ e tratados somente como causa:

Nesse caso, caracteristicamente - e como ratificação explícita de usos particulares -, há uma sofisticação aparente nessa área de crítica sobre causas e efeitos que estamos discutindo. É um determinismo tecnológico aparentemente sofisticado, que tem o importante efeito de indicar um determinismo social e cultural: um determinismo que, podemos dizer, ratifica a sociedade e a cultura que temos agora, especialmente seus direcionamentos internos mais poderosos. Se o meio de comunicação - a imprensa ou a televisão - é a causa, todas as outras causas, todas aquelas que os homens habitualmente entendem como história, estão imediatamente reduzidas a efeitos. De modo semelhante, o que, em outras pesquisas, é visto como efeito, e nessa condição sujeito ao questionamento social, cultural, psicológico e moral, está excluído como irrelevante por comparação com os efeitos fisiológicos diretos - e, por isso, psíquicos - dos meios de comunicação. A formulação inicial - "o meio é a mensagem" - era um simples formalismo. A formulação seguinte - "o meio é a massagem" - é uma ideologia direta e funcional (WILLIAMS, 2016, p. 136).

Nesse sentido Williams (2016) destaca que "[...]. Se o efeito do meio é sempre o mesmo, não importando quem o controle ou use, nem o conteúdo que se tente inserir, então podemos esquecer todo o debate político e cultural e deixar a tecnologia operar por si mesma" (p. 137).

Dessas reflexões provém a concepção de determinação em Williams, quando salienta sua oposição ao conceito de determinação como

[...] um conjunto de causas completamente controladoras e definidoras. Pelo contrário, a realidade da determinação é estabelecer limites e exercer pressões, dentro dos quais as práticas sociais variáveis são profundamente afetadas, mas não necessariamente controladas. Trata-se de pensar a determinação não como uma única força ou uma única abstração de forças, e sim como um processo em que fatores determinantes reais - a distribuição do poder ou de capital, a herança social ou física, as relações de escala e de tamanho entre grupos - colocam limites e exercem pressões, mas não controlam nem preveem completamente o resultado de uma atividade complexa nesses limites, sob ou contra essas pressões.

O caso da televisão é um exemplo excelente. Vimos que o processo complexo de sua invenção teve intenções específicas militares, administrativas e comerciais, e cada uma delas interagiu com o que foram - por períodos reais, ainda que limitados, ou de formas reais, ainda que limitadas - intenções científicas [...]" (WILLIAMS, 2016, p. 139).

Assim, o autor evidencia que a tecnologia pode ser utilizada para diferentes intenções com usos e efeitos imprevistos e exemplifica que a fabricação de explosivos sob o comando ou investimento de uma determinada classe, a dominante por exemplo, é feita com a intenção de lucro, mas que pode "[...] acabar usado por um grupo revolucionário contra essa mesma classe dominante ou por criminosos con-

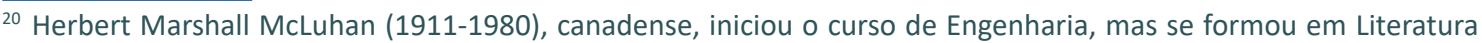
Inglesa em 1934 e doutorou-se em 1943. Foi professor universitário e autor de diversos livros e, por isso, é considerado o teórico das comunicações. Sua obra de destaque é "Os meios de comunicação como extensão do homem".
} 
tra a propriedade dessa indústria" (WILLIAMS, 2016, p. 139). Essa é a dupla função que o autor evidencia tanto na sua concepção sobre a televisão, suas causas e efeitos.

A partir do conceito de consciência em Vygostski e da concepção e função da televisão a partir de Raymond Williams, o próximo tópico terá como objeto as propagandas sobre a Reforma do Ensino Médio em que se tentará apreender o processo de legitimação de uma concepção de ensino mesmo em meio a protestos.

\section{A PROPAGANDA DA REFORMA DO ENSINO MÉDIO: Qual a Função da Consciência no Processo de Formação Humana?}

Utilizando-se de um discurso que destacava a ineficiência da escola pública e o desinteresse da juventude por ela, e sob a justificativa de tornar o Ensino Médio mais atraente de modo a diminuir os índices de abandono e melhorar os de avaliação em larga escala, a Reforma do Ensino Médio foi, inicialmente, apresentada pelo governo de Temer por meio da Medida Provisória no 746/2016 de 22 de setembro de $2016^{21}$.

Na sequência desta medida, em 28 de setembro de 2016 o Ministério da Educação começou a veicular duas propagandas na televisão, que, segundo o site do portal $\mathrm{MEC}^{22}$, apresentam detalhes das mudanças propostas pela Reforma do Ensino Médio. As peças têm duração de 60 segundos cada uma e foram gastos, segundo o site do $\mathrm{UOL}^{23}$, um total de $\mathrm{R} \$ 757.492,74$ para a produção destes comercias, além de gastos com propagandas em jornais e revistas.

Conforme o mesmo site de notícia, os comerciais foram emitidos gratuitamente por conta do convênio do Ministério da Educação com a Associação Brasileira de Emissoras de Rádio e Televisão - Abert. Esse convênio vigora desde 1991 e o atual findará em dezembro de 2019. A empresa que realizou a produção dos comerciais foi a Escala Comunicação e Marketing Ltda., contratada via licitação desde 2013.

A gratuidade das duas propagandas para o governo não quer dizer que se ofereça uma discussão com a sociedade, pois o intuito das mesmas, naquele momento, foi a de informar e não de estabelecer um debate com a sociedade.

Constatou-se que a proposta do Ensino Médio do Ministério da Educação teve como interlocutores as entidades de interesse privado ligadas ao Movimento Todos pela Educação ${ }^{24}$ e foi também pautada na pesquisa realizada pelo Centro Brasileiro de Análise e Planejamento - Cebrap - com o apoio da Fundação Victor Civita - FVC - com o

\footnotetext{
${ }^{21}$ A Reforma do Ensino Médio veio a ser viabilizada com a substituição da MP no 746 pelo PL 6.840/2013, que, aprovado pelo Congresso Nacional, foi promulgado com a Lei no 13.415, em 16 de fevereiro de 2017.

${ }^{22}$ Disponível em: http://portal.mec.gov.br/busca-geral/211-noticias/218175739/40941-anuncios-publicitariossobre-novo-ensino-medio-explicam-as-mudancas-propostas-pelo-mec. Acesso em: 21 ago. 2018.

${ }^{23}$ Disponível em: https://educacao.uol.com.br/noticias/2016/11/24/em-meio-a-ocupacoes-mec-gasta-r-18-mi-emcampanha-por-mp-do-ensino-medio.htm. Acesso em: 1ำ ago. 2018.

${ }^{24}$ Bezerra e Araújo (2017) trazem uma análise sobre a privatização do ensino por meio da Reforma do Ensino Médio e destacam como principais interlocutores para a reforma o empresariado. Ao final do artigo expõem a seguinte consideração: "Por fim, os pontos centrais da reforma do ensino médio foram calcados nas orientações dos think tanks do empresariado nacional (como o Movimento Todos pela Educação, Instituto Unibanco, dentre outros), aqui denominados, em conjunto, de reformadores empresariais da educação" (BEZERRA; ARAÚJO, 2017, p. 613).
} 
título $O$ que pensam os jovens de baixa renda sobre a escola, que ouviu mil jovens entre 15 e 19 anos que estavam cursando ou já concluíram o Ensino Médio e fazem parte dos 40\% mais pobres de São Paulo e Recife.

Faz-se necessário explicitar que a intencionalidade da nossa escolha para análise das duas propagandas veiculadas durante a proposição da MP, se dá pelo fato de estarmos em um momento controverso, tendo em vista que várias entidades ${ }^{25}$ se manifestaram contrariamente à proposta do governo já no momento da Medida Provisória - MP - e mesmo ao Projeto de Lei anterior sob no 6.84026, além da PEC 241 (na Câmara) ou PEC 55 (no Senado), hoje Emenda Constitucional no 95, promulgada em 15 de dezembro de 2016, que institui um novo regime fiscal. Nesse mesmo período houve mais de mil escolas ocupadas por estudantes secundaristas ${ }^{27}$ como forma de repúdio a essas medidas.

As propagandas, no entanto, apresentavam-se mais como uma preparação para a aceitação da Reforma do Ensino Médio pela população do que somente esclarecedoras. Por isso, vem com um objetivo bem-definido que é o de convencer que esta reforma trará benefícios aos estudantes, uma vez que menciona a experiência em outros países para essa efetivação, conforme propaganda 2. Segue na íntegra os diálogos das propagandas:

Propaganda 1: Atenção turma - na legenda aparece: Governo gasta $R \$ 1,8$ milhão em campanha a favor da reforma do ensino médio -, porque agora é hora de falar de educação. Vocês sabiam que a última avaliação da educação mostrou que o Brasil precisa melhorar muito no Ensino Médio? Isso mesmo! O desempenho dos jovens em matemática e português está menor do que há vinte anos. Duas décadas, gente! E hoje já são quase dois milhões de jovens que nem estudam e nem trabaIham. Preocupante, não é?! A gente precisa virar essa página. Melhorar a educação dos jovens é uma das tarefas mais importantes e urgentes no Brasil. É pra ontem! O novo ensino médio vai dar mais liberdade para você escolher as áreas do conhecimento de acordo com sua vocação e projeto de vida. Ou ainda optar pela formação técnica, caso queira concluir o ensino e já começar a trabalhar. Acesse o site e participe das discussões. Agora é você quem decide seu futuro.

\footnotetext{
25 Tais como: Movimento Nacional em Defesa pelo Ensino Médio; Sindicato Nacional dos Docentes das Instituições de Ensino Superior - Andes-SN; Associação Nacional de Pós-Graduação e Pesquisa em Educação - Anped; Confederação Nacional dos Trabalhadores em Educação - CNT; Centro de Estudos e Pesquisas em Educação, Cultura e Ação Comunitária - Cenpec; Ministério Público Federal; Sociedade Brasileira de Sociologia - SBS; Colégio Brasileiro de Ciência do Esporte; União Brasileira dos Estudantes Secundaristas - Ubes; Associação Brasileira de Hispanistas - ABH; Associação Brasileira de Educação Musical - Abem; Rede Federal de Educação Profissional Científica e Tecnológica - Conif; Associação Brasileira de Pesquisa e Pós-Graduação em Artes Cênicas - Abrace; Fórum Nacional de Educação - FNE; Frente Paraibana pela Escola em Defesa da Escola sem Mordaça; Federação Brasileira dos Professores de Francês - FBPF; Associação de Professores de Espanhol de São Paulo - APEESP; Associação de Linguística Aplicada do Brasil - Alab; Conselho Nacional dos Dirigentes das Escolas de Educação Básica das Instituições Federais de Ensino Superior - Condicap; entre outras. Disponível em: https://andesufrgs. wordpress.com/medida-provisoria-7462016-reforma-do-ensino-medio/. Acesso em 16 ago. 2018.

${ }^{26}$ Sugestão de leitura: SILVA, Monica Ribeiro; KRAWCZYK, Nora. Pesquisadoras "conversam" com PL 6.840 de reforma do Ensino Médio. Disponível em: http://www.observatoriodoensinomedio.ufpr.br/pesquisadoras-conversam-compl-6-840-de-reforma-do-ensino-medio/. Acesso em: 16 ago 2018.

${ }_{27}$ Movimento que ficou conhecido como primavera secundarista e teve mais de mil escolas ocupadas em, pelo menos, 7 Estados. Somente no Paraná foram 850 escolas ocupadas até o dia 25 de outubro de 2016. Cabe ressaltar que, neste movimento, várias universidades também foram ocupadas com a mesma finalidade.
} 
Propaganda 2: Aí, galera! Vocês já conhecem o novo Ensino Médio? Essa proposta que está todo mundo comentando por aí? Sabia que ela foi baseada nas experiências de vários países! - aparece na lousa: Coréia do Sul, França, Inglaterra, Portugal e Austrália - Países que tratam a educação como prioridade. E que ela vai deixar o aprendizado muito mais estimulante e compatível com a realidade dos jovens de hoje. Pois é! Agora além de apreender o conteúdo obrigatório essencial para a formação de todos e que será definido pela Base Nacional Comum Curricular já em discussão eu vou ter liberdade para escolher entre quatro áreas do conhecimento para me aprofundar. Tudo de acordo com minha vocação e com o que eu quero para minha vida. E para quem prefere terminar o ensino já preparado para começar a trabalhar poderá optar por uma formação técnica profissional com aulas teóricas e práticas. Acesse o site e participe das discussões. Agora é você que decide o seu futuro. Ministério da Educação Governo Federal. Ordem e Progresso.

A propaganda 1 ocorre no espaço escolar, em que a professora conversa com vários jovens numa sala de aula e todos prestam muita atenção ao que ela relata sobre a Reforma do Ensino Médio. Os alunos concordam com a professora quando fala sobre os dois milhões de jovens que não estudam e não trabalham como algo preocupante. Quando a atriz que representa a professora fala "O novo Ensino Médio vai dar mais liberdade para você escolher as áreas do conhecimento de acordo com sua vocação e projeto de vida", o semblante dos jovens mostra-se feliz.

A propaganda 2 evidencia os jovens conversando em sala de aula e um deles pede permissão para conversar com os colegas sobre a Reforma, e a professora concede. Inicia a fala de uma forma coloquial e próxima a dos jovens: "Aí, galera! Vocês já conhecem o novo Ensino Médio? Essa proposta que está todo mundo comentando por aí?". Neste momento a conversa cessa entre os jovens e todos prestam atenção no que o colega está falando. No momento em que o ator fala "[...] eu vou ter liberdade para escolher entre quatro áreas do conhecimento para me aprofundar", como na propaganda anterior, os jovens mostram um semblante feliz. Expressam essa felicidade quando o colega fala sobre a Educação Profissional.

Ambas as propagandas terminam com a indicação para acessar o site e participar das discussões, e salienta que "Agora é você quem decide seu futuro", falando diretamente com a pessoa que está assistindo.

A ênfase na escolha, caracterizada como protagonismo juvenil ${ }^{28}$, não é um termo novo na educação brasileira e pode ter várias interpretações. O destaque dada na atual reforma é de que o jovem pode decidir seu futuro e, ao fazer isso, torna-se responsável por suas escolhas se no futuro forem bem ou malsucedidas. Não há, no entanto, a explicação de que cada escola poderá "escolher" o itinerário que oferecerá, não sendo obrigatória a oferta de todos.

Questiona-se, então: Qual a escolha que esses alunos terão? Ah! Mas eles poderão escolher outras escolas públicas ou privadas que ofereçam o itinerário escolhido. Certo! Isso, porém, garantirá a escolha deste jovem? Será que é só escolher e pronto!?

\footnotetext{
${ }^{28}$ Para um melhor aprofundamento sobre este conceito, sugere-se a leitura de FERRETTI, Celso J.; ZIBAS, Dagmar M. L.; TARTUCE, Gisela Lobo B. P. Protagonismo Juvenil na literatura especializada e na reforma do Ensino Médio. In: Cadernos de Pesquisa, n. 34, n. 122, maio/ago. 2004. p. 411-423.
} 
Tudo se resolve? São questões para se pensar, além do fato da redução de conteúdos que, em nenhum momento, é dado como um problema, mas como a solução para um ensino muito "teórico".

As propagandas, ao explanarem um discurso fácil da crítica à escola pública de "pouco prática" e de "muito conteúdo desnecessário", utilizam-se das precárias condições materiais de existência dos mais pobres (os que precisam da escola pública) e repetidamente propõem uma escola rápida e prática (novo Ensino Médio) que promete "inserção rápida e bem-sucedida" ao mercado de trabalho, escondendo, neste discurso, o caráter de classe da reforma: formação adequada à exploração capitalista.

Apesar de a pesquisa realizada pela Cebrap apontar para uma certa aceitação dos jovens com relação à Reforma, observam-se comportamentos que resultam da não identificação de muitos jovens com a proposta do Ensino Médio; por exemplo, as críticas realizadas pelas entidades educacionais, mesmo que não seja na mídia televisiva dominante, causou um efeito não esperado que foram as ocupações das escolas. Esse processo de resistência foi possível com a reflexão sobre o que estava sendo proposto pelo governo e os reais impactos negativos da Reforma nas escolas não mencionados de forma explícita tanto na Medida Provisória quanto nas propagandas.

Essa dupla função da televisão, também mencionada por Williams, pode causar efeitos contrários aos propostos, no sentido de estabelecer limites e exercer pressão, conforme conceito de determinação já mencionado. Unida (se referindo a dupla função da televisão) ao caráter reflexivo da consciência, defendido por Vygotski, sofre uma interferência direta da linguagem, como também da atividade que as pessoas ocupam na sociedade, ou seja, é uma ação histórica e social.

A televisão, também considerada como um meio de controle, mas também de interação social, pode causar em algumas pessoas o propósito previsto como uma oposição a este. A que se deve tal fato?

Em primeiro lugar, por mais que o ser humano tente prever o comportamento do outro, esse é imprevisível conforme apontado por Vygotski, quando trata a consciência como um mecanismo de reflexão. Por refletir sobre as informações veiculadas e colocá-las numa cadeia de reflexos e conhecimentos, a consciência adquire um papel primordial na formação do ser humano, pois ativa a memória, a atenção e a percepção do entorno social para a formulação de conceitos. Isso é sentido a partir da realidade histórica, social e individual, por isso a imprevisibilidade do comportamento humano.

Por mais que as propagandas se utilizem de uma linguagem próxima de seu interlocutor - os jovens que serão alvo da reforma -, isso não quer dizer que haverá uma persuasão consensual. Mesmo que as propagandas tentem mostrar uma liberdade de escolha quando trazem como slogam final "Agora é você quem decide seu futuro", na prática não mostram como isso será viabilizado, o que pode gerar vários questionamentos da população em geral.

O prometido (e falso) "protagonismo do jovem" pode ser interpretado como uma tentativa de moldar sua consciência uma autorresponsabilização de sua precária condição, que pode ser sentida como individual, mas é social. 
Corroborando as reflexões, Williams chama atenção e faz uma crítica aos que veem as pessoas somente como expectadores:

[...]. No entanto, à medida que as intenções se tornaram efeitos, outra dimensão se abriu. Não foram somente grupos dominantes ou comerciais que reconheceram os problemas da comunicação em condições de uma mobilidade complexa e privatizada, mas também as muitas pessoas que experimentavam esse processo como sujeitos. Para aqueles que controlam e programam a televisão, essas pessoas podem parecer meros objetos: um público de espectadores ou um mercado. Mas do lado delas da tela, se estavam expostas de um novo modo, por necessidade, também estavam expostas a certas oportunidades incontroláveis. Essa interação complicada ainda se encontra em desenvolvimento (WILLIAMS, 2016, p. 140).

Essa perspectiva vem complementar o que se trouxe sobre a concepção da consciência em Vygotski, em que o homem age ativamente sobre a sociedade, diferente dos animais, e não é o mero receptor de estímulos como assim apregoavam e apregoam algumas Psicologias, como também não é algo somente subjetivo, meramente individual, mas social.

O que se pode perceber das propagandas em meio ao contexto social em que se colocou, foi a exacerbação das contradições sociais. Ou seja, não existe um consenso. Por mais que quem fez as propagandas ignore a existência das contradições e de disputas sociais, a sociedade expressa-se desta forma.

\section{ALGUMAS CONSIDERAÇÕES}

No término dessas reflexões aponta-se a proposição gramsciana que vem acrescentar, ao mostrar que há um espaço de disputas na sociedade capaz de formular contraideologias e serem disseminadas sem que seja preciso se utilizar de meios institucionalizados, como no caso aqui explicitado da televisão. As conversas com professores e o conhecimento das questões políticas pelos estudantes, compõem um arsenal de possibilidades que não pode ser projetado, mas se faz em meio a disputas.

Os meios de comunicação institucionalizados também mostram essa contradição e, por mais que se tenha um objetivo consensual, os dirigentes desses meios não têm o controle total do que as pessoas pensarão. Isso vem mostrar que o ser humano não é somente determinado pelo meio, mas participa ativamente por intermédio da experiência duplicada.

$\mathrm{O}$ fato de o homem poder reproduzir idealmente o mundo material e, a partir desta reprodução, interpretar esse mundo por meio de diversas mediações, é o que o forma, por isso as condições materiais são a base para esta formação e constituem também a cultura.

As propagandas do Ensino Médio analisadas podem mobilizar uma concordância ou discordância do conteúdo, mas exigem que a formação das pessoas as preparem para uma análise crítica de tais conteúdo. Nesse aspecto, ressalta-se a importância da educação no processo de mobilização da consciência no homem e na formação da experiência duplicada, ou seja, da relação entre as experiências histórica, social e individual. 


\section{REFERÊNCIAS}

ABERT. Convênio MEC. Disponível em: https://www.abert.org.br/web/index.php/2013-05-22-13-3319/2013-06-08-03-59-18/mec. Acesso em: 1ㅇaㅇ. 2018.

BEZERRA, Vinícius; ARAÚJO, Carla Maluf de. A reforma do Ensino Médio: privatização da política educacional. In: Revista Retratos da Escola, Brasília, v. 11, n. 21, jul./dez. 2017. p. 603-618. Disponível em: retratosdaescola.emnuvens.com.br/rde/article/download/779/pdf. Acesso em: 27 set. 2018.

CEVASCO, Maria Elisa. Questões de teoria. In: CEVASCO, Maria Elisa. Para ler Raymond Williams. São Paulo: Paz e Terra, 2001. p. 115-180.

FERRETTI, Celso J.; ZIBAS, Dagmar M. L.; TARTUCE, Gisela Lobo B. P. Protagonismo Juvenil na literatura especializada e na reforma do Ensino Médio. In: Cadernos de Pesquisa, n. 34, n. 122, maio/ago. 2004. p. 411-423.

MEC. Ministério da Educação. Assessoria de Comunicação Social. Anúncios publicitários sobre Novo Ensino Médio explicam as mudanças propostas pelo MEC. Brasília 31 out. 2016. Disponível em: http://portal. mec.gov.br/busca-geral/211-noticias/218175739/40941-anuncios-publicitarios-sobre-novo-ensino-medio-explicam-as-mudancas-propostas-pelo-mec. Acesso em: 27 jul. 2018.

PRAZERES, Leandro. Em meio a ocupações, MEC gasta $R \$ 1$ 1,8 mi em campanha por MP do Ensino Médio. Brasília, 24 nov. 2016. Disponível em: https://educacao.uol.com.br/noticias/2016/11/24/em-meio-a-ocupacoes-mec-gasta-r-18-mi-em-campanha-por-mp-do-ensino-medio.htm. Acesso em: 1ago. 2018.

SCHIAVONI, Jaqueline Esther. Televisão: tecnologia e forma cultural-dos usos e efeitos planejados aos usos e efeitos imprevistos. In: Significação, v. 43, n. 46, p. 230-237, 2016.

SILVA, Monica Ribeiro; KRAWCZYK, Nora. Pesquisadoras "conversam" com PL 6.840 de reforma do Ensino Médio. Disponível em: http://www.observatoriodoensinomedio.ufpr.br/pesquisadoras-conversam-com-pl-6-840-de-reforma-do-ensino-medio/. Acesso em: 16 ago. 2018.

TEÓRICOS DA COMUNICAÇÃO. Categoria: Marshall Macluhan. Disponível em: https://teoricosnocomando.wordpress.com/category/marshall-mcluhan/. Acesso em: 21 ago. 2018.

THE UNIVERSITY OF QUEENSLAND AUSTRALIA. Emeritus Professor Graeme Turner. Disponível em: https:// researchers.uq.edu.au/researcher/7479. Acesso em: 3 ago. 2018.

VYGOTSKI, Lev Semyonovich. Los métodos del investigación reflexológicos y psicológicos. In: VYGOTSKI, Lev Semyonovich. Obras escogidas Tomo I - problemas teóricos y metodológicos de la psicología. Madrid, p. 1-12, 1990a. Disponível em: http://www.taringa.net/perfil/vygotsky. Acesso em: 12 jul. 2018.

VYGOTSKI, Lev Semyonovich. La conciencia como problema de la psicología del comportamiento. In: VYGOTSKI, Lev Semyonovich. Obras escogidas Tomo I - problemas teóricos y metodológicos de la psicología. Madrid, p. 1-14, 1990b. Disponível em: http://www.taringa.net/perfil/vygotsky. Acesso em: 12 jul. 2018. WILLIAMS, Raymond. Televisão: tecnologia e forma cultural. Tradução Marcio Serelle e Mário E. I. Viggiano. 1. ed. 1974. São Paulo: Boitempo; Belo Horizonte, MG: PUCMinas, 2016. 